\title{
The Role of HIV-Related Knowledge and Ethnicity in Determining HIV Risk Perception and Willingness to Undergo HIV Testing Among Rural Women in Burkina Faso
}

\author{
Malabika Sarker, ${ }^{1,6}$ Andrea Milkowski, ${ }^{2}$ Tracy Slanger, ${ }^{3}$ Adam Gondos, ${ }^{1}$ \\ Aboubakary Sanou, ${ }^{4}$ Bocar Kouyate, ${ }^{4}$ and Rachel Snow ${ }^{5}$
}

Received August 4, 2003; revised July 26, 2004; accepted September 7, 2004

\begin{abstract}
We conducted a random community based survey of 300 young (15-29 years) rural women in Nouna, Burkina Faso. Only one-third of women were aware that a person could have HIV without having symptoms and these women were significantly more likely to classify themselves to be at high risk for getting HIV. Furthermore, multiple partners, Bwaba ethnicity and having mentioned a health worker as a source of HIV information were significantly associated with perceived high personal risk. Perceived willingness to participate in VCT was high (69\%). The dissemination of information on the asymptomatic nature of HIV infection could potentially be very important in forming risk perception, awareness, and their willingness to participate in HIV interventions.
\end{abstract}

KEY WORDS: VCT; PMTCT; Burkina Faso; risk perception; ethnicity; HIV; AIDS.

\section{INTRODUCTION}

Voluntary Counseling and Testing (VCT) and Prevention of Mother-to-Child Transmission (MTCT) have recently become a major focus of HIV control programs in developing countries (Dabis et al., 2000; De Cock et al., 2000). Short course antiretroviral therapy is effective against MTCT and programs are operational in many developing countries. VCT positively affects the subsequent

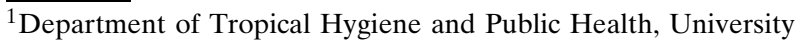
of Heidelberg, Germany.

${ }^{2}$ German Development Service Nairobi, Kenya.

${ }^{3}$ DKFZ (German Cancer Research Center), University of Heidelberg, Germany.

${ }^{4}$ Centre de Recherche en Sante de Nouna (CRSN), Nouna, Burkina Faso.

${ }^{5}$ Department of Health Behavior and Health Education, University of Michigan, Ann Arbor, USA.

${ }^{6}$ Correspondence should be directed to Malabika Sarker, Department of Tropical Hygiene and Public Health, University of Heidelberg, INF 324, 69120 Heidelberg, Germany; e-mail: malabika.sarker@urz.uni-heidelberg.de.
}

risk behavior of participants (The Voluntary HIV-1 Counseling and Testing Efficacy Study Group, 2000; Sangiwa et al., 2000; Wolitski et al., 1998) and, in connection with a prevention of MTCT (PMTCT) program, provides an opportunity to pregnant women to discuss HIV related issues with a qualified health provider. However, a number of studies have shown that the public acceptance of VCT and PMTCT services varies substantially in different settings (Cartoux et al., 1998a; Kowalczyk et al., 2002; Marjan and Ruminjo, 1996). Influencing factors include fear of stigmatization, discrimination, domestic violence or divorce, suspicion of already being infected, and lack of possible benefits of VCT (Cartoux et al., 1998a; Ladner et al., 1996; Temmerman et al., 1995). The better understanding of social and cultural factors that are locally relevant in a particular intervention context is critical to improving program design and successful implementation.

Burkina Faso, a West African country with a population of 13 million, is one of the poorest countries in the world. In 2002, HIV prevalence 
in the general adult population (15-49 years) and among urban antenatal care attendees was 6.5 and $6.3 \%$, respectively. HIV prevalence among antenatal care attendees in Ouahigouya, Gaoua and Tenkogo (outside the major urban areas) ranged from $2.8 \%$ to $13.4 \%$ (UNAIDS, 2002). The introduction of PMTCT is a component of the Burkina Faso National Strategy for HIV control; services are currently available in Ouagadougou, Bobo-Dioulasso, and Ouahigouya. Since no data existed on risk perception and willingness to undergo HIV testing among northwestern rural populations in Burkina Faso, we conducted this study to assess HIV/AIDS knowledge, risk perception and public demand for VCT and PMTCT intervention among young women residing in Nouna district town.

\section{METHODS}

\section{Study Population and Design}

The national demographic surveillance system (DSS) for 2001 listed 21,430 residents living within the seven sectors of Nouna town, of whom 3026 were women between 15 and 29 years of age. We drew a $10 \%(N=300)$, sector-weighted random sample of this population. For each participant, two additional same-sector replacements were randomly drawn, to be approached if the original woman was absent or refused to participate. Five local interviewers were recruited and trained in the use of the study questionnaire and the French questionnaire was translated into the local language Djula. The survey was conducted in March 2002. Participants were informed about the confidentiality of the data and a verbal consent was obtained. We had to approach 569 women to complete 300 interviews; 162 were not at home at the time of the interviewer's visit, 31 could not participate due to illness, 18 women had no identifiable address, 10 refused to participate and the remaining 48 were non-participants for other reasons. After data entry, we checked the validity of socio-demographic variables (age, parity, etc.) against the DSS data, and found it to be matching exactly.

HIV/AIDS-related questions, such as knowledge of HIV/AIDS, perception of personal and partner's risk, willingness to undergo HIV testing and interest in PMTCT were limited to women who responded that they had heard of HIV/AIDS $(n=$ 275). Questions related to willingness to undergo HIV testing were social proxy questions, for exam- ple, 'If a woman feels at risk of having AIDS, do you think she would like to do a test?' or 'If a woman is pregnant, do you think she would like to do a test?'. Demand for PMTCT was assessed after a brief description of the short course regimen of Nevirapine therapy, because of the possibility that many women might not have heard of a PMTCT program before.

\section{Statistical Methods}

For the description of different aspects of HIV/AIDS knowledge, all 300 women, regardless of whether or not they had heard of HIV/AIDS, were included in the denominator to provide a more complete view of the proportion of the population actually knowledgeable about HIV/AIDS. For assessments of risk perception and willingness to undergo testing, we excluded those who had not heard about HIV/AIDS $(n=25)$. We used multiple logistic regressions to identify the potential covariates of risk perception and perceived willingness to undergo HIV testing.

\section{RESULTS}

The majority of women (91\%) had heard of HIV/AIDS and two thirds (69\%) of the participants were aware that HIV/AIDS is a deadly disease. However, only $44 \%$ said that an infected person would become sick and only $31 \%$ of women were aware that a person can have HIV without having symptoms. Seventy seven percent indicated that the virus can be transmitted via sexual intercourse and 53\% mentioned at least one non-sexual mode of transmission (contaminated blood, razor, hair pin). Very few women had incorrect knowledge: only 6 women (2\%) stated that HIV can be transmitted through food or insect bites. However, only $46 \%$ mentioned condoms as a means of preventing HIV transmission. Regarding mother-to-child transmission, 77\% knew that an infant can become infected from an HIV positive mother, but only $62 \%$ knew any means to avoid infecting the infant. Of these, 54\% mentioned avoiding breast feeding, $18 \%$ mentioned taking medicine during pregnancy or delivery, and $23 \%$ mentioned parents' negative HIV status as being protective.

\section{Perception of Personal and Partner's Risk of HIV}

Among 275 women who had heard of HIV/ AIDS, $11 \%(n=30)$ considered themselves to be at 
high risk for getting HIV/AIDS and 9\% regarded themselves to be at medium risk. An additional 50\% of the participants considered themselves to be at low risk, $19 \%$ regarded themselves to be at no risk and $11 \%$ could not rank their risk. Some variation existed by ethnicity and self-reported risk for HIV: the Dafings, Samos, and Mossis perceived themselves mostly at no or low risk. Among the Bwaba, $22.5 \%$ classified themselves as at high risk. Among the Peulhs, none regarded themselves to be at high risk, whereas $21 \%$ said they were at medium risk.

Among women who had a partner $(n=215)$, nearly half $(44 \%)$ could not estimate their partner's risk of getting HIV. Among the remaining 114 women who did respond, there was a high overall correlation between women's perceptions of their own risk and that of their partners' risk (Spearman $R=0.79, p \leq .01$ ). Among 21 women who perceived themselves to be at high risk, only one woman reported that her partner was at no risk while 18 ranked their partners' risk as high.

Among the 30 women who regarded themselves to be at high risk for HIV, 18 women said it was because they had no trust in their partners and 2 reported they themselves had multiple partners. All those who identified their partners to be at high risk $(n=21)$ stated either that 'he has multiple partners' $(n=14)$ or that 'I do not trust him' $(n=7)$. Among women reporting that their partner was at no $(n=$ $19)$ or low $(n=61)$ risk, 100 and $90 \%$, respectively, reported that 'he is faithful to me.'

\section{Correlates of Risk Perception}

Knowledge about sexual transmission of HIV, and prevention through condoms were not related to women's perception of personal risk (see Table I). In multivariate logistic regression analysis, factors associated with perceived personal high risk of getting HIV/AIDS were: reporting multiple partners $(O R=40.86, p \leq 0.0001)$, belonging to the Bwaba ethnic group $(O R=14.52, p \leq 0.01)$, knowing that HIV infection can be asymptomatic $(O R=$ 16.9, $p \leq 0.001)$ and mentioning a health worker as a source for HIV/AIDS information $(O R=4.17$, $p \leq 0.03)$.

\section{Willingness to Test and Disclosure of HIV+ Status}

Sixty-nine percent of women reported that if a woman felt at risk of getting HIV/AIDS, she would go for testing (Table II).

Table I. Multiple Logistic Regression of Social Factors Associated With Perceiving One's Self to be At High Risk Versus No, Low or Medium Risk for HIV/AIDS $(n=275)$

\begin{tabular}{lcc}
\hline \multicolumn{1}{c}{ Variables } & Unadjusted $O R(95 \% C I)$ & Adjusted $O R(95 \% C I)$ \\
\hline Age & & \\
$\quad$ 15-19 years & 1.00 & 1.00 \\
20-29 years & $2.52(1.04,6.03)^{*}$ & $2.27(0.5,9.7)$ \\
Religion & 1.00 & 1.00 \\
$\quad$ Muslim & $1.26(0.57,2.80)$ & $0.42(0.1,2.8)$ \\
$\quad$ Christian & & \\
Ethnic Group & 1.00 & 1.00 \\
$\quad$ Peulh, Samo, Mossi, Dafing, Others & $4.29(1.51,12.17)^{* * *}$ & $14.52(1.7,126.7)^{* * *}$ \\
$\quad$ Bwaba & & \\
Formal education/schooling & 1.00 & 1.00 \\
$\quad$ None & $0.70(0.28,1.71)$ & $1.04(0.2,5.3)$ \\
$\quad$ Primary & $0.64(0.24,1.70)$ & $1.04(0.2,6.5)$ \\
$\quad$ Secondary & & 1.00 \\
Perception that HIV is asymptomatic & 1.00 & $16.9(2.9,99.3)^{* * *}$ \\
$\quad$ No & $21.00(4.78,92.31)^{* * *}$ & \\
$\quad$ Yes & & 1.00 \\
HIV/AIDS Information received from health worker & 1.00 & $4.16(1.1,16.0)^{*}$ \\
$\quad$ No & $3.52(1.60,7.69)^{* * *}$ & \\
$\quad$ Yes & & 1.00 \\
Reporting multiple partners ${ }^{a}$ & 1.00 & $40.87(8.6,193.8)^{*}$ \\
$\quad$ No & $51.5(18.3,145.2)^{* * *}$ & \\
$\quad$ Yes &
\end{tabular}

${ }^{a}$ Women who reported that they have multiple partners or reported that they do not trust their partner.

*Significant at $* 0 \leq 0.05 ;{ }^{* *} p \leq 0.01 ;{ }^{* * *} p \leq 0.001$. 
Table II. Attitudes Toward HIV Testing, PMTCT Services and HIV Positive Status Disclosure ${ }^{a}$

\begin{tabular}{lc}
\hline & Yes (\%) \\
\hline Perceptions about women's willingness to undergo HIV testing & $190(69 \%)$ \\
If a woman feels at risk of having AIDS, do you think she would like to do a test? & $237(86 \%)$ \\
If a woman is HIV+, could she convince her partner to have an HIV test? & $228(83 \%)$ \\
Would a woman take her baby for HIV testing? & $253(92 \%)$ \\
Perceptions about women's willingness to participate in PMTCT services & \\
If a woman is pregnant, do you think that she would like to have an HIV test? & $207(75 \%)$ \\
If a woman is pregnant and learns that she has HIV, what do you think she would prefer to do thereafter?: & $5(2 \%)$ \\
- Take medication (to reduce the chances that the baby has HIV) & $56(20 \%)$ \\
- Undergo an abortion & $7(3 \%)$ \\
- Trust in God: & $171(62 \%)$ \\
- Does not know & $148(55 \%)$ \\
Perceptions about women's ability to disclose HIV positive status ${ }^{b} .$. & $75(27 \%)$ \\
If a woman knows that she is HIV positive, could she share that with her partner? & \\
If a woman knows that she is HIV positive, could she share that with her family? & \\
If a woman knows that she is HIV positive, could she share that with her friends? &
\end{tabular}

${ }^{a}$ Responses were limited to those who had heard of HIV/AIDS $(n=275)$.

${ }^{b}$ Multiple answers possible.

In multivariate analysis (data are not shown here), perceived willingness of women to undergo HIV testing was significantly associated with being younger (15-19 vs. 20-29 years) $(O R=0.55,95 \% C I$ : $0.30-0.99, p \leq 0.05)$ and having received HIV/AIDS information from a health worker $(O R=2.4,95 \%$ CI: $1.2-4.9, p \leq .01$ ) (data not shown). Following a brief description of the planned PMTCT services (provision of short course antiretroviral therapy, the perceived willingness to participate in a PMTCT program was almost universal (92\%). In addition, when asked, 'if a woman is pregnant and learns that she has $H I V$, what do you think she would prefer to do?' $75 \%$ mentioned taking medication, $20 \%$ said trust in God and only $2 \%$ mentioned abortion.

Sixty-two percent of women reported that 'If a woman knows that she is HIV positive, she could share that with her partner,' whereas 55 and $27 \%$ mentioned family and friends, respectively. Women who attended secondary school were significantly more likely to say that women could disclose their HIV positive status.

\section{DISCUSSION}

The majority of women in our study (89\%) perceived themselves as to be at some risk of HIV infection. A 'lack of trust' in a male partner, and a 'partner's promiscuity' were the most common reasons given for perceived high personal risk, in accordance with other studies, which have found that the greatest HIV risk for a married woman is her part- ner (De Zoysa et al., 1996; Heise and Elias, 1995; Kengeya-Kayondo et al., 1999; Ventura-Filipe et al., 2000). The high correlation between women's personal perceived risk and their partner's risk shows that women correctly understand that a couple's risk is bound together.

The strong association between perceiving oneself to be at high risk and knowing that HIV can be asymptomatic is plausible. Women who are aware that a person can carry the HIV virus without symptoms may feel more at risk because they know that they might get infected by any apparently healthy partner. Those unaware of this on the other hand may believe that only sick looking, in practice terminally ill persons may pose a risk for transmission-a false and potentially dangerous perception.

We found that women who had received HIV/AIDS information from a health worker were significantly more likely to perceive themselves to be at high risk compared to those who obtained their information elsewhere. Mass media messages are often the principal means of communicating scientific health information to the general population. Although the quality and correctness of the information are often high, this means of communication rarely allows for further clarification (Taverne, 1999; Painter, 2001), a factor that may explain the above finding.

Bwaba women were significantly more likely to classify themselves at high risk. There are several possible explanations for this finding. Historically, the status of women among the Bwaba has been different from other ethnic groups. Bwaba culture 
was seen to be comparatively less conservative and less patriarchal than the predominant Mossi ethnic group (Nazi, 1962). Bwaba women are responsible for brewing beer, an essential social and economic activity of women, crucial for maintaining social status and connection within the village. Bwaba girls tend to marry later and there is greater tolerance for outof-wedlock births than among other ethnic groups (Kevane and Wydick, 2001). Retel-Laurentin in 1973 found that half of the Bwaba women in her study had a stable marriage, but the other half ended in de facto divorce, with woman typically leaving the husband for another man. In contrast, $90 \%$ of Mossi marriages were stable, ending only with death of the partner (Capron and Kohler, 1978). Bwaba women are able to exercise considerable freedom and control over their activities (Capron, 1981), which might result in greater openness about HIV risk, or greater actual risk.

The majority (69\%) of women believed that a woman would go for HIV testing if she felt to be at risk. Seventy-seven percent of our study participants mentioned that a baby can get HIV from their mother, and, prior to the information provided on PMTCT services within the context of the survey questionnaire, $62 \%$ of women already knew at least one way to prevent mother-to-child-transmission, a strong increase over the $8 \%$ of women who reported MTCT awareness in Bobo-Dioulasso 6 years ago (Cartoux et al., 1998b). This rise was most likely due to education campaigns about vertical transmission by non government organizations (NGOs), such as GRAAP, (ORSTOM, 1995) and mass media messages.

After a short presentation on the PMTCT program, the perceived willingness to test during pregnancy was almost universal (92\%), comparable to the PMTCT program in Bobo-Dioulasso, where $92.4 \%$ of pregnant women consented to HIV testing (Cartoux et al., 1998b). The difference between perceived willingness to participate in VCT and PMTCT underscores that a perceived benefit from participation is a crucial factor for acceptance of HIV testing (Fylkesnes et al., 1999; Meadows et al., 1993).

Burkina Faso needs a strong HIV prevention program. First of all, migration plays a significant role in the economic and cultural life of Burkina Faso, a factor that was shown to play a critical role in the spread of HIV from the very beginning of the epidemic (Dawson, 1988; UNAIDS, 2001). Temporary migration from Nouna District to the Ivory Coast, the country with the highest HIV prevalence in the region, is not uncommon (Wladarsch, 2003). Secondly, polygamy is legally possible and practiced in Burkina Faso, with around 33\% of married women between 15 and 29 years having at least one cowife. Proportions are higher in rural areas (EDSBFII, 1998-1999). Thereby an infected partner is a potential source of infection for not only one, but more spouses.

Current use of condom in women is $2.5 \%$ in Burkina Faso (EDSBF-II, 1998-1999). The HIV prevention program in Burkina Faso needs to be improved by a widespread condom promotion campaign and ensuring the regular supply of free condoms to rural areas. In the programs, along with providing information on the modes of transmission and prevention, additional focus on the asymptomatic nature of HIV is needed. It has been documented that a major factor motivating women to participate in HIV testing programs is the perception of personal risk for HIV (Maman et al., 2001; Meadows and Catalan, 1994). VCT may be very effective in providing HIV knowledge and the opportunity for clarification through counseling might enable participants to correctly judge their own risk for getting HIV/AIDS.

Study participants correctly understood that their own and their partner's risk is bound together. In addition, $38 \%$ of the women believed that a woman could not disclose her seropositive status to her partner. Women often fear that disclosure of their HIV seropositive status to a partner may lead to domestic violence, discrimination, stigmatization, and disruption of personal relations (Issiaka et al., 2001; Gaillard et al., 2002, Garcia-Moreno and Watts, 2000; Heyward et al., 1993; Kilewo et al., 2001). Both of these factors underline the importance of male involvement in a PMTCT program. As a recent evaluation of PMTCT programs in several developing countries has demonstrated, involving male partners can make a real difference in improving women's uptake of PMTCT services (Horizon Report, 2003). The introduction of VCT for males in a PMTCT program should therefore be pursued generally.

\section{ACKNOWLEDGMENTS}

We gratefully acknowledge the cooperation of the Centre de Recherche en Sante de Nouna (CRSN) in Burkina Faso, and the interviewers and the participation of women in Nouna, for making this study possible. Special thanks are owed to H. Becher, G. Kynast-Wolf, A. Gbangou and S.A. Ouedraogo for 
assistance with sampling within the CRSN demographic surveillance system (DSS), and to A Pale and A Gbangou for assistance with training of interviewers. We also grateful to Rainer Sauerborn, who provided financial support for the study from the collaborative research grant 'Control of Tropical Infectious Diseases', Sonderforschungsbereich (SFB 544), Heidelberg University (Germany), and we gratefully acknowledge the ongoing intellectual support of our partners in the SFB 544 (A6) project: H.G. Kräusslich, T. Böhler and D. Manga Tebit.

\section{REFERENCES}

Capron, J., and Kohler, J. M. (1978). De quelques characteristiques de la pratique matrimoniale mossi contemporaine. In C. Oppong, G. Abada, M. Bekombo-Priso, and J. Mogley (Eds.), Marriage, fertility and parenthood in West Africa. Canberra: The Australian National University.

Capron, J. (1981). Des Femmes et Une Societe pour l'avenir. Working paper, Ministere de l'ensegnement superieur et de la recherche scientifique, Center national de la recherche scientifique et technologique, Ouagadougou, Haute Volta.

Cartoux, M., Meda, N., Van de Perre, P., Newell, M. L., de Vincenzi, I., and Dabis, F. (1998a). Acceptability of voluntary HIV testing by pregnant women in developing countries an international survey. AIDS, 12, 2489-2493.

Cartoux, M., Msellati, P., Meda, N., Welffens-Ekra, C., Mandelbrot, L., and Dabis, F. (1998b). Attitude of pregnant women towards HIV testing in Abidjan, Cote d'Ivoire and Bobo-Dioulasso, Burkina Faso. AIDS, 12, 2337-2344.

Dabis, F., Newell, M. L., Fransen, L., Cartoux, M., Meda, N., Whynes, D. K., et al. (2000). Prevention of mother to child transmission of HIV in developing countries: Recommendations for practice. Health Policy and Planning, 15, 34-42.

Dawson, M. H. (1988). AIDS in Africa: Historical roots. In N. Miller and R. Rockwell (Eds.), AIDS in Africa, The social and policy impact (pp. 57-69). Studies in African Health and medicine. Lewiston, U.S.A.: The Edwin Mellen Press.

De Cock, K. M., Fowler, M. G., Mercier, E., de Vincenzi, I., Saba, J., Hoff, E., et al. (2000). Preventing mother to child transmission of HIV in resource poor countries: Translating research in to policy and practice. Journal of the American Medical Association, 283, 1175-1182.

De Zoysa, I., Sweat, M. D., and Denison, J. A. (1996). Faithful but fearful: Reducing HIV transmission in stable relationships. AIDS, 10, S197-S203.

Enquête Démographique et de Santé au Burkina Faso, 1998-1999 (EDSBF-II).

Fylkesnes, K., Haworth, A., Rosensvard, C., and Kwapa, P. M. (1999). HIV counseling and testing: Overemphasizing high acceptance rates a threat to confidentiality and the right not to know. AIDS, 13, 2469-2474.

Gaillard, P., Melis, R., Mwanyumba, F., Claeys, P., Muigai, E., Mandaliya, K., Bwayo, J., and Temmerman, M. (2002).Vulnerability of women in an African setting: Lessons for mother-to-child HIV transmission prevention programs. AIDS, 16, 937-939.

Garcia-Moreno, C., and Watts, C. (2000). Violence against women: Its importance for HIV/AIDS. AIDS, 14, S253-S265.

Heise, L. L., and Elias, C. (1995). Transforming aids prevention to meet women's needs: A focus on developing countries. Social Science and Medicine, 40, 931-943.
Heyward, W. L., Batter, V. L., Malulu, M., Mbuyi, N., Mbu, L., St Louis, M. E., Kamenga, M., and Ryder, R. W. (1993). Impact of HIV counseling and testing among child-bearing women in Kinshasa, Zaire. AIDS, 7, 1633-1637.

Horizons Report, Operational research on HIV/AIDS (2003). PMTCT from research to practice. Population Council. http:// www.popcouncil.org/horizons/newsletter/horizons(7).html.

Issiaka, S., Cartoux, M., Ky-Zerbo, O., Tiendrebeogo, S., Meda, N., Dabis, F., and Van de Perre, P.; Ditrame Study Group. (2001). Living with HIV: Women's experience in Burkina Faso, West Africa. AIDS Care, 13, 123-128.

Kengeya-Kayondo, J. F., Carpenter, L. M., Kintu, P. M., Nabaitu, J., Pool, R., and Whitworth, J. A. (1999). Risk perception and HIV-1 prevalence in 15000 adults in rural south-west Uganda. AIDS, 13, 2295-2302.

Kevane, M., and Wydick, B. (2001). Social Norms and the Time Allocation of Women's Labor in Burkina Faso. Review of Development Economics, 5, 119-129.

Kilewo, C., Massawe, A., Lyamuya, E., Semali, I., Kalokola, F., Urassa, E., Giattas, M., Temu, F., Karlsson, K., Mhalu, F., and Biberfeld, G. (2001). HIV counseling and testing of pregnant women in sub-Saharan Africa: Experiences from a study on prevention of mother-to-child HIV-1 transmission in Dar es Salaam, Tanzania. Journal of Acquired Immune Deficiency Syndromes and Human Retrovirology, 28, 458462.

Kowalczyk, J., Jolly, P., Karita, N. J., Vyankandondera, J., and Salihu, H. (2002). Voluntary counseling and testing for hiv among pregnant women presenting in labor in Kigali, Rwanda. Journal of Acquired Immune Deficiency Syndromes and Human Retrovirology, 31, 408-415.

Ladner, J., Leroy, V., Msellati, P., Nyiraziraje, M., De Clerq, A., Van de Perre, P., and Dabis, F. (1996). A cohort study of factors associated with failure to return for HIV post-test counseling in pregnant women: Kigali, Rwanda, 1992-1993. AIDS, $10,69-75$.

Maman, S., Mbwambo, J., Hogan, N. M., Kilonzo, G. P., and Sweat, M. (2001) Women's barriers to HIV-1 testing and disclosure: Challenges for HIV-1 voluntary counseling and testing. AIDS Care, 13, 595-603.

Marjan, R. S., and Ruminjo, J. K. (1996).Attitudes to prenatal testing and notification for HIV infection in Nairobi, Kenya. East African Medical Journal, 73, 665-669.

Meadows, J., and Catalan, J. (1994). Why do antenatal attendees decide to have the HIV antibody test? International Journal of STD and AIDS, 5, 400-404.

Meadows, J., Catalan, J., and Gazzard, B. (1993). "I plan to have the HIV test"-predictors of testing intention in women attending a London antenatal clinic. AIDS Care, 5, 141148.

Nazi, B. (1962). Crépuscule des temps anciens. Paris: Présence Africaine.

ORSTOM incentive "Social Sciences and AIDS" (1995). Review (contd) Burkina Faso, Congo, Ivory Coast SOCIÉTÉS D'AFRIQUE and SIDA N 9 July 1995 pp. 6-9.

Painter, T. M. (2001). Voluntary counseling and testing for couples: A high-leverage intervention for HIV/AIDS prevention in sub-Saharan Africa. Social Science and Medicine, 53, 13971411.

Retel-Laurentin, A. (1973). "Evasions Féminines dans la Volta Noire." Cahiers d'Etudes Africaines, 19, 253-298.

Sangiwa, G. M., Straten, A., Grinstead, O., and the VCT Study Group. (2000). Clients' perspective of the role of voluntary counseling and testing in HIV/AIDS prevention and care in Dar Es Salaam, Tanzania: The VCT efficacy study. AIDS and Behavior, 4, 35-48.

Taverne, B. (1999). Representations of MTCT of AIDS, perception of the risk and health information messages in Burkina Faso. Sante, 9, 195-199. 
Temmerman, M., Ndinya-Achola, J., Ambani, J., and Piot, P. (1995). The right not to know HIV-test results. Lancet North American Edition, 15, 345, 969-970.

The Voluntary HIV-1 Counseling and Testing Efficacy Study Group. (2000). Efficacy of voluntary HIV-1 counseling and testing in individuals and couples in Kenya, Tanzania, and Trinidad: A randomized trial. Lancet, 356, 103-112.

UNAIDS (2002). Epidemiological fact sheets on HIV/AIDS and sexually transmitted infections; Burkina Faso 2002 Update, Geneva. UNAIDS, 2002.

UNAIDS (2001). Population mobility and AIDS: Technical update. Geneva: UNAIDS, 2001

Ventura-Filipe, E. M., Bugamelli, L. E., Leme, B., Santos, N. J., Garcia, S., Paiva, V., and Hearst, N. (2000). Risk perception and counseling among HIV positive women in Sao Paulo, Brazil. International Journal of STD and AIDS, 11, 112114.

Wladarsch, E. (2003). 'Patience is the future!-Cultural conceptions of time and their manifestation in health-related time preferences in rural Burkina Faso: An interdisciplinary approach between Anthropology and Public Health. Doctoral thesis submitted to the Faculty of behavioral and cultural sciences at the University of Heidelberg, Nov. 2003.

Wolitski, R. J., MacGowan, R. J., Higgins, D. L., and Jorgensen, C. M. (1998). The effects of HIV counseling and testing on risk related practices and help seeking behavior. AIDS Education and Prevention, 9, 52-67. 